\title{
Monotherapy versus triple therapy antibiotics for the management of perforated appendicitis in children
}

\author{
Mohamed E Hassan, MD
}

\author{
Associate Professor of Pediatric Surgery, Zagazig University, Egypt.
}

Introduction: Appendicitis is the most common surgical emergency in the pediatric population. Despite the widespread prevalence of the disease, there is little consensus regarding the diagnosis and management of appendicitis. The aim of the study is to compare the surgical outcome of laparoscopic appendectomy in children for perforated appendicitis using perioperative triple versus a single antibiotic based regimen.

Patients and methods: A retrospective review was done for all the children who had a laparoscopic appendectomy for perforated appendicitis in a tertiary pediatric surgery center in UAE in the period from June 2009 to January 2014. A total of 56 children was included in the study. Group A, monotherapy group 'MG'(31 cases) who were managed with piperacillin/ tazobactam and group B, triple therapy group 'TG' (25 cases) who were managed with Amoxicillin Clavulanate, Metronidazole and amikacin.

Results: There were 52\% males and 48\% females, mean age were $8.3 \pm 1.5$ years. There were $26 \%$ cases versus 28\% cases in MG and TG respectively who required more than 7 days antibiotics. Mean total length of hospital stay was statistically significant more in TG than $M G$. There was significant difference between both groups (13\% versus $36 \%$ in $M G$ and $T G$ respectively) for the need to replace the IV cannula before 72 hours.

Conclusion: Monotherapy antibiotic management of perforated appendix in children was equally effective as triple antibiotic therapy in the current study population for the infectious morbidities. Monotherapy antibiotic management showed significant less incidence of intravenous cannula morbidities and shorter total hospital stay.

Key words: Appendix, laparoscopy, children, antibiotics.

\section{Introduction:}

Appendicitis is the most common surgical emergency in the pediatric population. Despite the widespread prevalence of the disease, there is little consensus regarding the diagnosis and management of appendicitis. ${ }^{1}$

Although many physicians would argue that "standard therapy" consists of an aminoglycoside, a B -lactam, and an antibiotic with anaerobe coverage (ie, ampicillin, gentamicin, or metronidazole), ${ }^{2-5}$ These medications are individually inexpensive; however, each is administered multiple times per day, creating a complex dosing schedule. Gentamicin is an aminoglycoside with known renal and ototoxic side effects that requires the measurement of serum levels. Although this regimen has been safe and reliably effective, contemporary antibiotics allow a large selection of drugs that do not require laboratory monitoring. 6

Increasing evidence suggests that single-agent antibiotic therapy provides equivalent results, compared with multiagent regimens. ${ }^{7-9}$

The aim of the study is to compare the surgical outcome of laparoscopic appendectomy in children for perforated appendicitis using perioperative triple versus a single antibiotic based regimen.

\section{Patients and methods:}

A retrospective file review was done for all the children who had a laparoscopic 
appendectomy for perforated appendicitis in a tertiary governmental pediatric surgery center in UAE in the period from June 2009 to January 2014.

Exclusion criteria included children who had conversion to open appendectomy and children who received another antibiotic regimen.

A total of 56 children was included in the study. Patients were divided into two groups, according to the type of antibiotic regimen used, Group A, monotherapy group 'MG' (31 cases) who were managed with piperacillin/ tazobactam and group $B$, triple therapy group 'TG' (25 cases) who were managed with Amoxicillin Clavulanate, Metronidazole and amikacin.

The following data were collected, patient demographics, pre and postoperative white blood cell count (WBCs) and C reactive protein (CRP), preoperative and postoperative fever (the mean of the daily maximum temperature), operative time, intraoperative findings (generalized versus localized peritonitis), the total length of hospital stay, surgical site infection (SSI), postoperative residual intraperitoneal collection, need to replace the intravenous (IV) cannula before 72 hours and 1 month follow up results.

Data were collected, tabulated and statistically analyzed using SPSS 17 . Chi square (for qualitative data) and t test (for quantitative data) were calculated to test for the significant differences between the groups, $\mathrm{P}<0.05$ was considered as statistically significant difference.

\section{Perioperative management:}

Diagnosis of appendicitis was done based on clinical, laboratory and abdominal ultrasound findings, CT scan was done in very selected cases of doubtful diagnosis. All the cases received a single dose preoperative Amoxicillin Clavulanate within 30 minutes before surgery.

Surgical procedure were standard for all the cases. 3 ports were used, umbilical, suprapubic and left iliac fossa. Mesoappendix was divided with monopolar diathermy and the base of the appendix was ligated with absorbable endoloop (EL, 2/0 polydioxanone PDS, Ethicon Endosurgery, Inc. Cincinnati, $\mathrm{OH}$, USA), the appendix was retrieved from the umbilical port.

Perforated appendix was defined as an appendix found intraoperatively to have a hole, the hole was not iatrogenic during surgery. Gangreanous appendix was considered as perforated appendix.

Residual intraabdominal collection was defined as any postoperative intraabdominal collection after surgery diagnosed by ultrasound associated with fever and aspirated fluid was positive for the culture.

Surgical site infection was defined as any discharge from any of the wounds within one month of surgery associated with redness, tenderness and/or fever.

CRP and WBCs were repeated on the $3^{\text {rd }}$ and $5^{\text {th }}$ postoperative days. Patients were discharged when the CRP was less than 20, decreasing WBCs and there was no fever for 24 hours without the use of antipyretic medications. If CRP was still high and / or WBCs not decreasing (Regardless of the temperature scale), antibiotics were continued for more 3 days then investigations repeated, if it was still high, Ultrasound and/or CT scan was obtained and managed accordingly. Patients were reviewed in the outpatient clinic 1 month after discharge.

Piperacillin/tazobactam dose was 80 $\mathrm{mg} / \mathrm{kg} /$ dose 8 hourly (maximum $4 \mathrm{gm} /$ dose), Amoxicillin Clavulanate $30 \mathrm{mg} / \mathrm{kg} /$ dose 8 hourly (maximum $1.2 \mathrm{gm} /$ dose), Metronidazole $10 \mathrm{mg} / \mathrm{kg} /$ dose (maximum $500 \mathrm{mg} / \mathrm{dose}$ ) and Amikacin $7.5 \mathrm{mg} / \mathrm{kg} / \mathrm{dose}$ every 12 hours. All the intravenous cannulas were changed every 72 hours of insertion according to our hospital policy.

\section{Results:}

There was 29 (52\%) males and 27 (48\%) females in the study, mean age in the study was $8.3 \pm 1.5$ years, Table (1).

The mean values of the temperature for both groups are illustrated in Figure (1). Details of the mean WBCs count and CRP values pre and postoperatively is shown in Figures $(2,3)$ respectively. Mean operative 


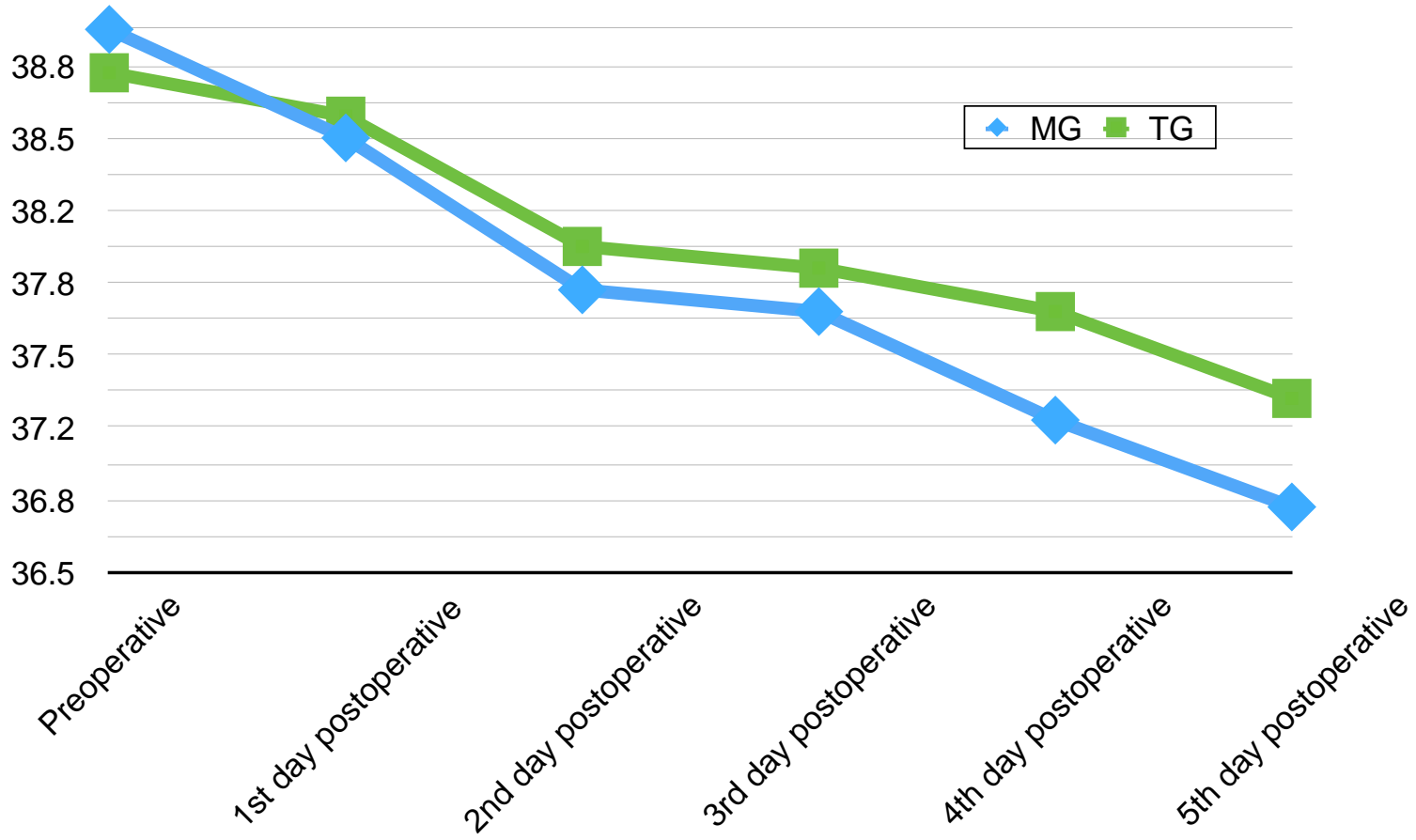

Figure (1): Mean values of pre and postoperative temperature for both groups.

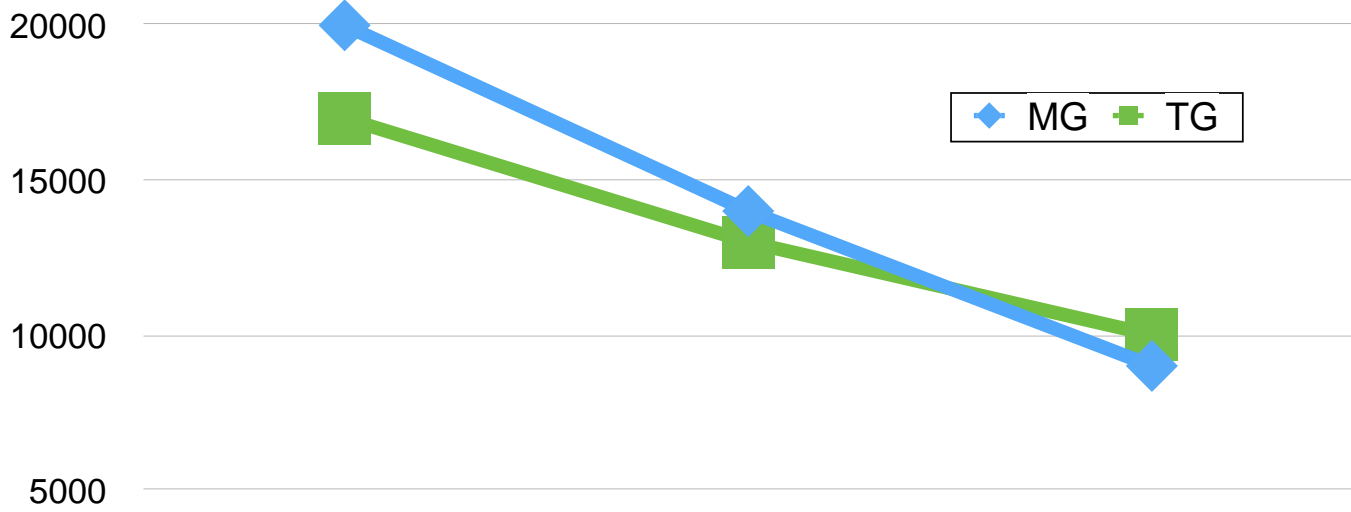

Preoperatively 3rd day postoperatively 5 th day postoperatively

Figure (2): Pre and postoperative values of the mean WBCS for both groups.

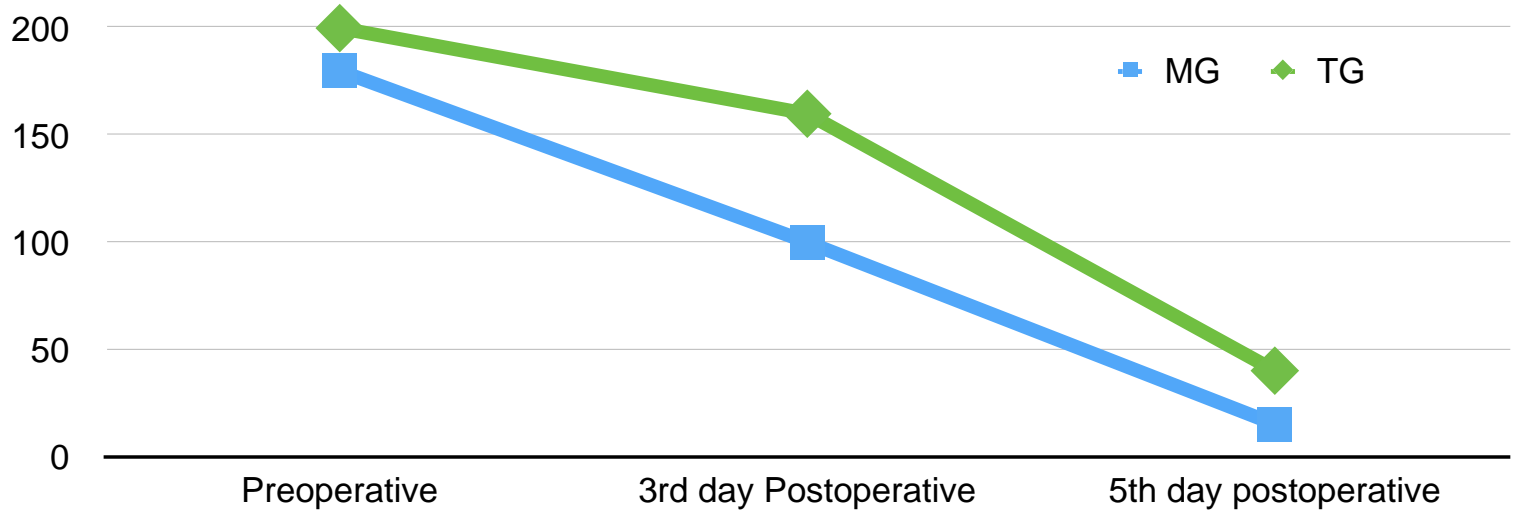

Figure (3): Pre and postoperative mean CRP values for both groups. 
Table 1: Demographics for both groups.

\begin{tabular}{|l|l|l|l|l|}
\hline \multicolumn{2}{|l|}{ Variables } & MG (31) & TG (25) & X2/ t, P \\
\hline \multirow{2}{*}{ Gender } & Male & 15 & 14 & X2 $=0.3$ \\
\cline { 2 - 5 } & Female & 16 & 11 & $\mathrm{P}>0.05$ \\
\hline \multirow{2}{*}{ Age (Years) } & $8.8 \pm 2$ & $9.2 \pm 1.3$ & $\begin{array}{l}\mathrm{t}=0.9 \\
\mathrm{P}>0.05\end{array}$ \\
\hline Weight (KG) & $32 \pm 2.3$ & $33.5 \pm 2.7$ & $\begin{array}{l}\mathrm{t}=2.2 \\
\mathrm{P}<0.05\end{array}$ \\
\hline
\end{tabular}

Table 2: Variables in both groups.

\begin{tabular}{|c|c|c|c|c|}
\hline Variables & & MG (31) & TG (25) & $\mathrm{X} 2 / \mathrm{t}, \mathrm{P}$ \\
\hline \multirow[t]{2}{*}{ Intraoperative findings } & Generalized peritonitis & $10(32 \%)$ & $5(20 \%)$ & \multirow{2}{*}{$\begin{array}{l}X 2=1.06 \\
P>0.05\end{array}$} \\
\hline & Localized peritonitis & $21(68 \%)$ & $20(8 \%)$ & \\
\hline \multicolumn{2}{|c|}{ Mean total length of hospital stays (days) } & $7 \pm 1.5$ & $8.5 \pm 2$ & $\begin{array}{l}t=3.2 \\
P<0.05\end{array}$ \\
\hline \multicolumn{2}{|l|}{ Surgical site infection } & $3(9 \%)$ & $3(12 \%)$ & $\begin{array}{l}\mathrm{X} 2=0.1 \\
\mathrm{P}>0.05\end{array}$ \\
\hline \multirow{2}{*}{$\begin{array}{l}\text { Postoperative residual } \\
\text { intraperitoneal collection }\end{array}$} & Treated conservatively & $7(22.5 \%)$ & $6(24 \%)$ & \multirow{2}{*}{$\begin{array}{l}X 2=0.2 \\
P>0.05\end{array}$} \\
\hline & Required drainage & 0 & $1(4 \%)$ & \\
\hline \multicolumn{2}{|c|}{$\begin{array}{l}\text { Need to change the intravenous (IV) cannula before } 72 \\
\text { hours }\end{array}$} & $4(13 \%)$ & $9(36 \%)$ & $\begin{array}{l}\mathrm{X} 2=4.1 \\
\mathrm{P}<0.05\end{array}$ \\
\hline \multicolumn{2}{|c|}{ Complications after 1 month postoperatively } & 0 & $1(4 \%)$ & $\begin{array}{l}\mathrm{X} 2=1.3 \\
\mathrm{P}>0.05\end{array}$ \\
\hline
\end{tabular}

time for MG was $45 \pm 10$ minutes versus $52 \pm 20$ minutes for $\mathrm{TG}(\mathrm{t}=1.7, \mathrm{P}>0.05)$.

There were 8 (26\%) cases versus 7 (28\%) cases in MG and TG respectively required more than 7 days of IV antibiotics (X2 $=0.034$, $\mathrm{P}>0.05$ ).

Table (2) shows variables in both groups, there was one case in TG case of adhesive bowel obstruction that required adhesiolysis.

\section{Discussion:}

Appendicitis is the most common indication for urgent abdominal surgery in the pediatric population, and ruptured appendicitis affects a large proportion of those patients. ${ }^{10}$ Minimizations of morbidity, cost, hospital length of stay, and readmissions remain primary objectives of surgical management. Postappendectomy infection relates to all of these measurable outcomes, and the choice of antibiotic regimens has a major effect on each of these parameters. ${ }^{10}$
Almost $60 \%$ of surgeons base their clinical practice in the management of perforated appendicitis on their individual preferences. ${ }^{11}$

There was no statistically significant differences in the gender and age between both groups. TG showed statistically significant more weight, which is expected due to older mean age for the TG than MG.

There is grade $\mathrm{B}$ evidence that the length of administration of IV antibiotics should be based on clinical criteria, such as fever, pain, return of bowel function, and white blood cell (WBC) count. ${ }^{12,13}$ In the current study, temperature scale showed that MG reached the normal range $\left(37.2{ }^{\circ} \mathrm{C}\right)$ on the 4th postoperative day, while for TG the mean temperature was $37.3{ }^{\circ} \mathrm{C}$ on the 5 th postoperative day. The WBCs scale was almost similar for both groups, while the CRP scale showed more sloping decrease in the MG than TG.

Although $26 \%$ versus $28 \%$ in $\mathrm{MG}$ 
and TG required antibiotic regimen more than 7 days, which didn't reach statistical significant difference, there was statistically significant more mean time of total hospital stay for TG than MG. In concordance to the current study, Adam et al $^{10}$ retrospective study of 8545 children showed longer hospital stay in the triple antibiotics group (aminoglycoside based combination therapy) than monotherapy group (Ceftriaxone or Piperacillin/ tazobactam). Nadler et al $^{9}$ didn't show significant differences between the study groups regarding the length of hospital stay.

Intraoperative findings, SSI and postoperative residual intraperitoneal collection didn't reach statistically significant differences between both groups in the current study. In contrary, Nadler et $\mathrm{al}^{9}$ showed significantly higher postoperative infectious complications in the multiagent antibiotics group than Piperacillin/ tazobactam group.

In accordance to Nadler et al, ${ }^{9}$ there was statistically significant difference between both groups (13\% versus 36\% in MG and TG respectively) for the need to replace the IV cannula before 72 hours, which is attributed to the occurrence of thrombophlebitis due to frequent injections. As IV cannula insertion is very annoying procedure in children, even with the use of local anesthetic during insertion, we think venous access morbidities should be always looked for in planning antibiocs management in children.

The down side of the current study is the small number of the study population and it is a retrospective study. But it highlighted several findings that it will be of value to be studied in a prospective well designed study with larger population.

\section{Conclusion:}

Monotherapy antibiotic management of perforated appendix in children was equally effective as triple antibiotic therapy in the current study population for the infectious morbidities. Monotherapy antibiotic management showed significant less incidence of intravenous cannula morbidities and shorter total hospital stay.

\section{Reference:}

1- Lee SL, Islam S, Cassidy LD, Abdullah F, Arca MJ: Antibiotics and appendicitis in the pediatric population: An American Pediatric Surgical Association Outcomes and Clinical Trials Committee systematic review. J Pediatr Surg. 2010; 45(11): 2181-21815.

2- Lund DP, Murphy EU: Management of perforated appendicitis in children: A decade of aggressive treatment. J Pediatr Surg 1994; 29: 1130-1133.

3- Firilas AM, Higginbotham PH, Johnson DD, Jackson RJ, Wagner CW, Smith SD: A new economic benchmark for surgical treatment of appendicitis. Am Surg 1999; 65: 769-773.

4- Emil S, Laberge JM, Mikhail P, et al: Appendicitis in children: A ten-year update of therapeutic recommendations. J Pediatr Surg 2003; 38: 236-242.

5- Meier DE, Guzzetta PC, Barber RG, Hynan LS, Seetharamaiah R: Perforated appendicitis in children: Is there a best treatment? $J$ Pediatr Surg 2003; 38: 1520-1524.

6- St Peter SD, Little DC, Calkins CM, et al: A simple and more cost-effective antibiotic regimen for perforated appendicitis. $J$ Pediatr Surg 2006; 41: 1020-1024.

7- Ciftci AO, Tanyel FC, Buyukpamukcu N, Hicsonmez A: Comparative trial of four antibiotic combinations for perforated appendicitis in children. Eur J Surg 1997; 163: 591-596.

8- Fishman SJ, Pelosi L, Klavon SL, O’Rourke EJ: Perforated appendicitis: Prospective outcome analysis for 150 children. J Pediatr Surg 2000; 35: 923-926.

9- Nadler EP, Reblock KK, Ford HR, Gaines BA: Monotherapy versus multi-drug therapy for the treatment of perforated appendicitis in children. Surg Infect (Larchmt) 2003; 4: 327-333.

10- Goldin AB, Sawin RS, Garrison MM, Zerr DM, Christakis DA: Aminoglycoside-based triple-antibiotic therapy versus monotherapy for children with ruptured. Appendicitis Pediatrics 2007; 119: 905.

11- Chen C, Botelho C, Cooper A, Hibberd P, Parsons SK: Current practice patterns in the treatment of perforated appendicitis in children. J Am Coll Surg 2003; 196: 212-221.

12- Lelli JL, Drongowski RA, Ravi S, et al: Historical changes in the postoperative treatment of appendicitis in children: impact on medical outcome. J Pediatr Surg 2000; 35: 239-245. 
13- Fraser, et al: A complete course of intravenous antibiotics versus a combination of intravenous and oral antibiotics for perforated appendicitis in children: A prospective randomized trial. $J$ Pediatr Surg 2010; 45: 1198-1202. 